\title{
BMJ Open Readability assessment of package leaflets of biosimilars
}

\author{
María Ángeles Piñero-López, Carlos Figueiredo-Escribá, Pilar Modamio, \\ Cecilia F Lastra, Eduardo L Mariño
}

To cite: Piñero-López MÁ, Figueiredo-Escribá C, Modamio P, et al. Readability assessment of package leaflets of biosimilars. BMJ Open 2019;9:e024837. doi:10.1136/ bmjopen-2018-024837

- Prepublication history for this paper is available online. To view these files, please visit the journal online (http://dx.doi. org/10.1136/bmjopen-2018024837).

Received 22 June 2018 Revised 14 September 2018 Accepted 27 November 2018

Deck for updates

(c) Author(s) (or their employer(s)) 2019. Re-use permitted under CC BY-NC. No commercial re-use. See rights and permissions. Published by BMJ.

Clinical Pharmacy and Pharmacotherapy Unit, Department of Pharmacy and Pharmaceutical Technology, and Physical Chemistry, Faculty of Pharmacy and Food Sciences, University of Barcelona, Barcelona, Spain

Correspondence to Prof Pilar Modamio; pmodamio@ub.edu

\begin{abstract}
Objectives To assess the degree of readability and the length of the package leaflets of biosimilars.

Setting The package leaflets analysed were downloaded from the European Medicines Agency (EMA) website.

Participants The study sample included the package leaflets written in English of all the biosimilars that were authorised by the EMA on 31 August 2017, and whose content was available via the internet on that date $(n=35)$. Design This was a cross-sectional analytical study. The readability of the package leaflets of all biosimilars authorised by the EMA in August 2017 was determined applying the Flesch and Flesch-Kincaid formulas. The influence of the following variables on the readability and length was also analysed: package leaflet section, type of biosimilar, date of first authorisation of the biosimilar and type of medicine.

Results $A$ considerable variation of the package leaflets length was found $(3154 \pm 803)$. The readability of all the package leaflets overtook the recommended value for health-related written materials taking into account Flesch-Kincaid Index, and none of the package leaflets were easy to understand according to the Flesch Index. Statistically significant differences $(p<0.05)$ were observed between the sections of package leaflets in readability indices and length. The most difficult sections to understand were those related with the therapeutic indication of medicine and the possible side effects. Conclusions Package leaflets for authorised biosimilars may not fulfil the function for which they were designed. The competent organisations could be informed about the possible negative effect on the use of this type of medicines.
\end{abstract}

\section{INTRODUCTION}

According to the European Medicines Agency (EMA), a biological product is one that contains one or more active substances derived from a biological source. ${ }^{1}$ A biosimilar is 'a biological medicinal product that contains a version of the active substance of an already authorised original biological medicinal product (reference medicinal product) in the European Economic Area'. ${ }^{2}$ Biosimilars have shorter clinical development programmes than the corresponding reference medicines, ${ }^{3}$ and undergo regulatory processes that make use of prior experiences
Strengths and limitations of this study

The study addresses a gap in the current evidence regarding determination of readability of biosimilar package leaflets in the European Union.

- Readability formulas can be considered as a first step to identify understanding problems in health-related written materials.

- One weakness of the study was that no patients were consulted. Therefore, these results could be complemented with direct methods of evaluation of readability with patients.

with the reference medicines. ${ }^{4}$ The active substance of a biosimilar and that of its reference medicine are essentially the same biological substance, but they do have differences due to the complexity of their nature and the methods of production, ${ }^{1}$ which do not affect the safety or the effectiveness of the medicine. ${ }^{5}$ The aim of developing biosimilar medicines was to reduce the price of the medicines and to promote competition in the pharmaceutical market. ${ }^{6}$

Biosimilars can only be authorised once the period of exclusivity of the reference biological medicine has expired. ${ }^{1}$ In the European Union (EU), the first biological product patents expired in 2001, and it was not until several years later, in 2006, that the EMA approved the first biosimilar. ${ }^{7}$ Since then, EMA has pioneered the regulation of this type of medicinal products for human use. $^{8}$ However, once a biosimilar has been approved, the policies adopted by different European countries with respect to the use of biosimilars present differences concerning the extent to which this type of medicinal product is promoted. ${ }^{9}$ There are also notable differences at the intercontinental level regarding the clinical development and use of biosimilars, as can be seen by comparing the EU and the USA. ${ }^{10}$

The existence of reliable information on medicines, which is up to date and can be accessed by patients, is vital so that the patients 
can participate in shared decision-making regarding their treatment. This has become even more important at the current stage of the development of biosimilars, ${ }^{11}$ as a consequence of the considerable and increasing number of biosimilars that are now available on the market. ${ }^{12}$ One source of information on medicines, and the most commonly consulted by patients, is the package leaflet, ${ }^{13}$ which is defined as 'a leaflet containing information for the user which accompanies the medicinal product'. ${ }^{14}$ The package leaflet is crucial in the transmission of information related to medicines to citizens, as it can help to complement and reinforce the information received from healthcare professionals, ${ }^{15}$ which in turn can increase adherence and, in general, suitable use of medicinal products. To help improve the writing of package leaflets and make them easy for patients to read and understand, in 2009, the European Commission published its 'Guideline on the readability of the label and package leaflet of medicinal products for human use', in which it provided guidance on good writing for labelling and package leaflets, with the aim of making them easier to understand. ${ }^{16}$

One aspect that influences correct comprehension of written material is, in general, the level of literacy of the public. ${ }^{17}$ Therefore, health literacy influences the understanding of health-related written materials (which is precisely what package leaflets are). According to Nutbeam, ${ }^{18}$ 'health literacy represents the cognitive and social skills which determine the motivation and ability of individuals to gain access to, understand and use information in ways which promote and maintain good health'. Insufficient health literacy is related to a reduction in adherence, ${ }^{19}$ and it is also considered a barrier that prevents people from accessing healthcare systems. ${ }^{20}$

Another aspect that should be taken into account when it comes to arriving at an appropriate interpretation of a text is its readability, which indicates how easy it is to understand the text, in accordance with the style of writing adopted. ${ }^{21}$ According to EU Directive 2004/27/ EC, 'the package leaflet must be written and designed to be clear and understandable, enabling the users to act appropriately, when necessary with the help of health professionals'. ${ }^{22}$ The readability of a text can be objectively measured using readability formulas, which are commonly used to measure the readability of different types of health-related written materials, ${ }^{23}{ }^{24}$ many of which are available on the internet. ${ }^{25}$ It is recommended that health-related written materials do not have a level of readability beyond the sixth grade level (ages 11-12), ${ }^{26}$ and this is also true of package leaflets. Meanwhile, if health-related written materials are excessively long, this could make them more difficult to understand. ${ }^{17}$

Taking into account the forecast growth in the market of biosimilars in the coming years, ${ }^{27}$ studying the readability of the package leaflets of biosimilars that are currently on the market is an important task. Therefore, the objective of this study was to determine and assess the degree of readability and the length of the package leaflets of all the biosimilars authorised by the EMA on 31 August
2017 , and also to study the influence of certain categorical variables on these quantitative variables. We believe that the results will allow us to assess the suitability of the writing of package leaflets with regards to the needs of the patient, and if it is found not to meet those needs, to warn of the possible need to modify the contents.

\section{METHODS}

\section{Study type, selection criteria and source of the sample}

We designed a cross-sectional analytical study. The study sample included the package leaflets written in English of all the biosimilars that were authorised by the EMA on 31 August 2017, and whose content was available via the internet on that date $(n=35)$. These package leaflets were downloaded from the EMA website, ${ }^{28}$ on 31 August 2017.

\section{Patient and public involvement}

Patients and/or public were not involved.

\section{Sample characteristics}

The biosimilars studied ( $\mathrm{n}=35$ ) included human growth hormones, insulins, granulocyte-colony stimulating factors, erythropoietins, follitropins ${ }^{29}$ and, since more recently, low-molecular-weight heparins, parathyroid hormones and monoclonal antibodies (table 1).

Five of the six sections that commonly make up package leaflets were studied ${ }^{30}$ : ' 1 . What $\mathrm{X}$ is and what it is used for' $(\mathrm{n}=35)$, ' 2 . What you need to know before you $<$ take $>$ $<$ use $>\mathrm{X}$ ' $(\mathrm{n}=35)$, ' 3 . How to $<$ take $><$ use $>\mathrm{X}$ ' $(\mathrm{n}=35)$, '4. Possible side effects' ( $\mathrm{n}=35)$ and ' 5 . How to store $\mathrm{X}$ ' $(n=35)$. We excluded section ' 6 . Contents of the pack and other information' as it was similar for all the package leaflets and, moreover, the content of this section is not considered very important by the patient. ${ }^{31}$ We also evaluate the 'Annex' in those package leaflets which had one $(n=16)$, which includes useful handling instructions for the patient.

The sections of the package leaflets to be evaluated were copied without any format into individual Microsoft Word 2013 (Microsoft Corporation) documents, and before calculating the quantitative variables, the following modifications were performed, according to instructions of authors' formulas. In this way, we deleted all titles, subtitles, tables and their headings, graphics, images, figure legends and references, as well as the commercial name of the medicinal product and all bullet points (hyphens, numbers, asterisks, etc); all abbreviations, units, magnitudes and numbers were replaced by their meaning in words; acronyms were also replaced by their meaning if it had already appeared in the text; if it had not, then they were replaced by the transcription of the letters.

Figure 1 shows an example of the modifications carried out on the texts (package leaflets) prior to determining the values of the quantitative variables. 
Table 1 Biosimilars studied $(n=35)$

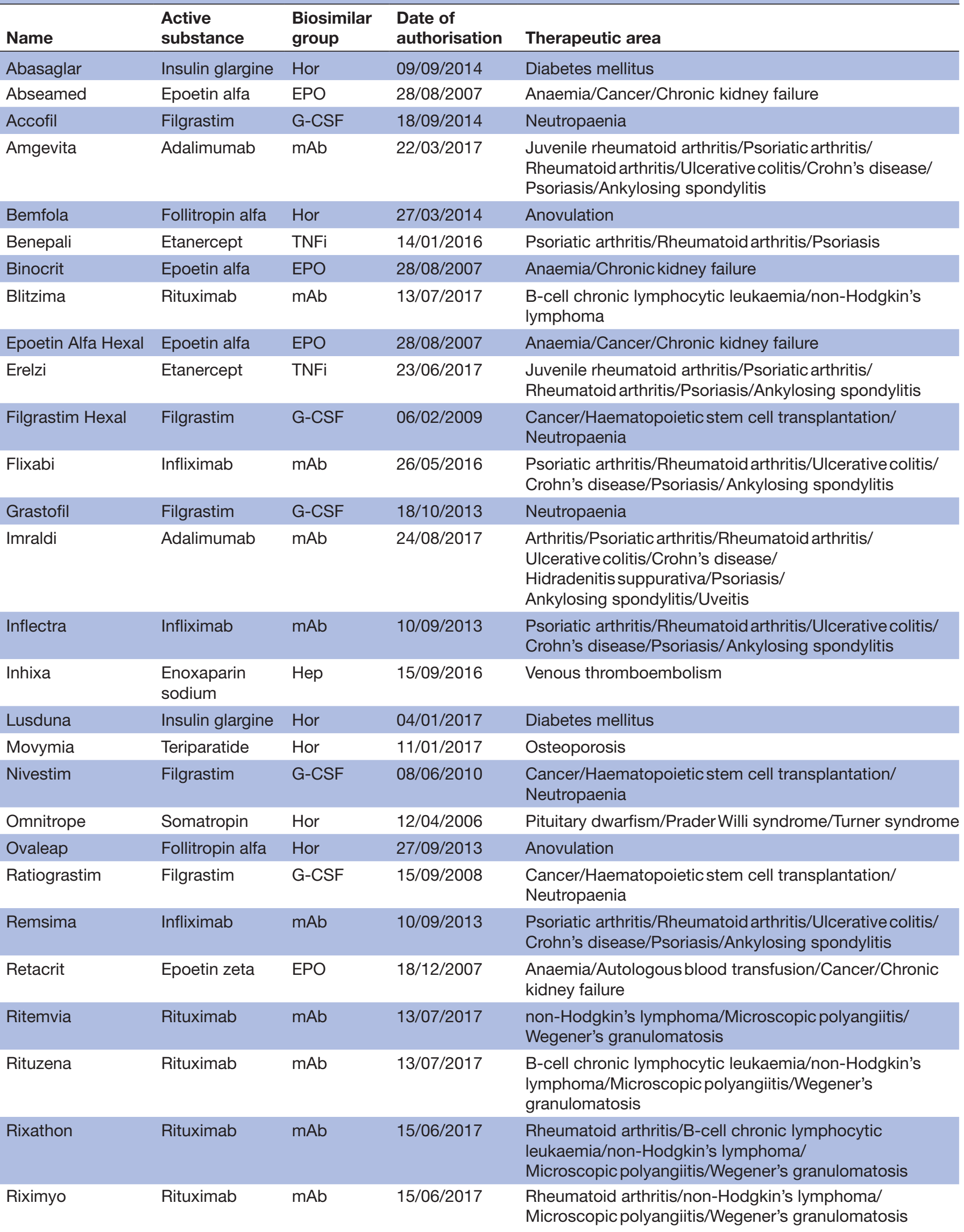


Table 1 Continued

\begin{tabular}{|c|c|c|c|c|}
\hline Name & $\begin{array}{l}\text { Active } \\
\text { substance }\end{array}$ & $\begin{array}{l}\text { Biosimilar } \\
\text { group }\end{array}$ & $\begin{array}{l}\text { Date of } \\
\text { authorisation }\end{array}$ & Therapeutic area \\
\hline Silapo & Epoetin zeta & EPO & $18 / 12 / 2007$ & $\begin{array}{l}\text { Anaemia/Autologous blood transfusion/Cancer/Chronic } \\
\text { kidney failure }\end{array}$ \\
\hline Solymbic & Adalimumab & $\mathrm{mAb}$ & $22 / 03 / 2017$ & $\begin{array}{l}\text { Psoriatic arthritis/Rheumatoid arthritis/Ulcerative colitis/ } \\
\text { Crohn's disease/Hidradenitis suppurativa/Psoriasis/ } \\
\text { Ankylosing spondylitis }\end{array}$ \\
\hline Tevagrastim & Filgrastim & G-CSF & $15 / 09 / 2008$ & $\begin{array}{l}\text { Cancer/Haematopoietic stem cell transplantation/ } \\
\text { Neutropaenia }\end{array}$ \\
\hline Thorinane & $\begin{array}{l}\text { Enoxaparin } \\
\text { sodium }\end{array}$ & Hep & $15 / 09 / 2016$ & Venous thromboembolism \\
\hline Truxima & Rituximab & $\mathrm{mAb}$ & $17 / 02 / 2017$ & $\begin{array}{l}\text { Rheumatoid arthritis/B-cell chronic lymphocytic } \\
\text { leukaemia/non-Hodgkin's lymphoma/ } \\
\text { Microscopic polyangiitis/Wegener's granulomatosis }\end{array}$ \\
\hline
\end{tabular}

EPO, erythropoietins; G-CSF, granulocyte-colony stimulating factors; Hep, heparins; Hor, hormones; mAb, monoclonal antibodies; TNFi, tumour necrosis factor alpha inhibitors.

\section{Quantitative variables}

From the sections of the package leaflets, we determined the length of the texts (total number of words), and the readability as established by two indices: the Flesch Index ${ }^{32}$ and the Flesch-Kincaid Index. ${ }^{33}$ These two readability indices were chosen taking into account the following criteria: (1) the Flesch and Flesch-Kincaid formulas are the most commonly used in the literature related to health ${ }^{34}$; and (2) the two numerical values obtained using these formulas require different

\begin{tabular}{|c|c|}
\hline Original text & Modified text \\
\hline \multicolumn{2}{|l|}{ 5. How to store ABASAGLAR } \\
\hline Keep this medicine out of the sight and reach of children. & Keep this medicine out of the sight and reach of children. \\
\hline $\begin{array}{l}\text { Do not use this medicine after the expiry date which is } \\
\text { stated on the carton and on the label of the pen after } \\
\text { "EXP". The expiry date refers to the last day of that month. }\end{array}$ & $\begin{array}{l}\text { Do not use this medicine after the expiry date which is } \\
\text { stated on the carton and on the label of the pen after "EXP". } \\
\text { The expiry date refers to the last day of that month. }\end{array}$ \\
\hline Not in-use pens & \\
\hline $\begin{array}{l}\text { Store in a refrigerator }\left(2^{\circ} \mathrm{C}-8^{\circ} \mathrm{C}\right) \text {. Do not freeze. } \\
\text { Do not put ABASAGLAR next to the freezer compartment } \\
\text { or a freezer pack. } \\
\text { Keep the pre-filled pen in the outer carton in order to } \\
\text { protect from light. }\end{array}$ & $\begin{array}{l}\text { Store in a refrigerator (two to eight Celsius degrees). Do not } \\
\text { freeze. Do not put next to the freezer compartment or a } \\
\text { freezer pack. Keep the pre-filled pen in the outer carton in } \\
\text { order to protect from light. }\end{array}$ \\
\hline $\begin{array}{l}\text { In-use pens } \\
\text { Pre-filled pens in use or carried as a spare may be stored } \\
\text { for a maximum of } 28 \text { days up to } 30^{\circ} \mathrm{C} \text { and away from } \\
\text { direct heat or direct light. The pen in use must not be } \\
\text { stored in a refrigerator. Do not use it after this time period. } \\
\text { The pen cap must be put back on the pen after each } \\
\text { injection in order to protect from light. }\end{array}$ & $\begin{array}{l}\text { Pre-filled pens in use or carried as a spare may be stored } \\
\text { for a maximum of twentyeight days up to thirty Celsius } \\
\text { degrees and away from direct heat or direct light. The pen } \\
\text { in use must not be stored in a refrigerator. Do not use it } \\
\text { after this time period. The pen cap must be put back on the } \\
\text { pen after each injection in order to protect from light. }\end{array}$ \\
\hline $\begin{array}{l}\text { Do not throw away any medicines via wastewater or } \\
\text { household waste. Ask your pharmacist how to throw away } \\
\text { medicines you no longer use. These measures will help } \\
\text { protect the environment. }\end{array}$ & $\begin{array}{l}\text { Do not throw away any medicines via wastewater or } \\
\text { household waste. Ask your pharmacist how to throw away } \\
\text { medicines you no longer use. These measures will help } \\
\text { protect the environment. }\end{array}$ \\
\hline
\end{tabular}

Figure 1 Example of modifications that were made in the evaluated sections of the package leaflets before calculating quantitative variables. 
interpretations, which can help with cross-checking the results.

The Flesch-Kincaid Index (FKGL or in full Flesch-Kincaid Grade Level) indicates the educational level required to understand a text, ${ }^{33}$ given as the number of years of education after the age of 6 . For example, an FKGL of 6 indicates that the reading level is equivalent to age 11 to 12, while an FKGL of 7 indicates a reading level equivalent to age 12 to 13, and so on. In contrast, the Flesch Index (FRE or in full Flesch Reading Ease) indicates how easy a text is to read, and relates the value obtained with the following qualitative evaluation of the text: $90-100$, very easy; $80-90$, easy; $70-80$, fairly easy; $60-70$, standard; $50-60$, fairly difficult; $30-50$, difficult; and 0-30, very difficult. ${ }^{32}$ As can be seen, the two readability indices considered are inversely proportional: as a text becomes easier to read, the FKGL value goes down and the FRE goes up.

We also considered it advisable to assess the length of the texts, given that it has been shown that the longer a package leaflet, the more difficult it is to find information, the less motivated the patient feels to read it and the less confident the patient feels regarding the use of the medicine, after having read it. ${ }^{35}$

The three quantitative variables (length, FKGL and FRE) were determined directly using the Microsoft Word 2013 'readability statistics' tool (Microsoft Corporation).

\section{Qualitative variables}

The influence of the following qualitative variables on the length and readability of the package leaflets was also studied.

1. Section of package leaflet: ' 1 . What $X$ is and what it is used for' $(n=35)$, '2. What you need to know before you $<$ take $><$ use $>\mathrm{X}$ ' $(\mathrm{n}=35)$, '3. How to $<$ take $><$ use $>$ $X^{\prime}(n=35)$, '4. Possible side effects' $(n=35)$, ' 5 . How to store X' $(\mathrm{n}=35)$ and 'Annex' $(\mathrm{n}=16)$.

2. Type of biosimilar, establishing six groups (table 1): erythropoietins $(n=5)$, granulocyte-colony stimulating factors $(n=7)$, heparins $(n=2)$, hormones $(n=7)$, monoclonal antibodies $(\mathrm{n}=12)$ and tumour necrosis factor alpha inhibitors $(n=2)$.

3. Date of the first authorisation of the biosimilar, establishing two values for the variable: biosimilars first authorised in 2006-2014 ( $\mathrm{n}=18)$; and those authorised in 2015-2017 ( $\mathrm{n}=17)$. This chosen cut-off (2014-2015) was because no statistically significant differences in the readability of package leaflets of biological medicines were observed in a previous longitudinal research between 2007 and 2013, despite the European guidance of readability published in $2009 .{ }^{36}$

4. Type of medicine, establishing two values of this variable: biosimilars $(\mathrm{n}=35)$ and their respective reference medicines $(n=7)$. In this case, we only included those active substances whose package leaflets were available online from the EMA website.

For the first qualitative variable (package leaflet section), we considered the values of the quantitative variables (length and readability indices) obtained directly.
However, for the other qualitative variables, in order to have a single value per package leaflet of each quantitative variable, we considered the average values calculated from the values obtained in the individual sections, in the case of the readability indices, and the total, in the case of length. In addition, in the last comparative study, the average of the biosimilars with the same active substance was calculated for each quantitative variable to obtain a single value per active substance.

\section{Statistical analysis}

Statistical calculations were performed and graphics were designed using the software Deducer (R V.3:15:0). We applied the Shapiro-Wilk test of normality to all the groups of values. Taking into account the normality results, we applied non-parametric hypothesis tests in all the comparative studies in which each quantitative variable was studied as a function of the qualitative variables. We used the Kruskal-Wallis test to compare the different sections of the package leaflet and the types of biosimilars; the Mann-Whitney U test in the comparative study of the date of first authorisation of the biosimilar; and the Wilcoxon signed-rank test to contrast the biosimilars with their reference medicine. In all the hypothesis tests, we considered a level of significance of 0.05 when accepting or rejecting the null hypothesis.

\section{RESULTS}

Table 2 shows the main descriptive statistics of the three quantitative variables for each package leaflets analysed. A large variation can be seen in the total length of the package leaflets $(3154 \pm 803)$. Taking into account the Flesch Index, none was easy of understand (all the averages were below 70). Furthermore, according to the Flesch-Kincaid Index, all the package leaflets were more difficult to read than is recommended for health-related texts (all the averages were over 6).

In relation to the comparative study of the quantitative variables as a function of the section of the package leaflet, figure 2 and table 3 show descriptive statistics of each section. When we applied the Kruskal-Wallis test, we observed statistically significant differences $(p<0.05)$ between the six sections in all three quantitative variables (length, Flesch Index and Flesch-Kincaid Index). These differences appeared between pairs of sections when we applied post hoc pairwise comparisons. The results show the following decreasing order for the length of the sections of the package leaflets of the biosimilars, from longest section to shortest: '4. Possible side effects' > '3. How to $<$ take $><$ use $>\mathrm{X}$ ' $>$ '2. What you need to know before you $<$ take $><$ use $>X^{\prime}>$ 'Annex' $>$ ' 1 . What $\mathrm{X}$ is and what it is used for' $>$ ' 5 . How to store $X$ '. In terms of the readability of the respective sections, the following decreasing order of readability was observed, from the section that was most easy to understand to the most difficult: 'Annex' > '5. How to store X' > '3. How to <take $>$ $<$ use $>\mathrm{X}$ ' > '2. What you need to know before you $<$ take $>$ $<$ use $>\mathrm{X}$ ' > '4. Possible side effects' > '1. What $\mathrm{X}$ is and 
Table 2 Length and readability indexes by package leaflet $(n=35)$

\begin{tabular}{|c|c|c|c|}
\hline & Length & FRE & FKGL \\
\hline Name & Total & Mean (SD) & Mean (SD) \\
\hline Abasaglar & 3760 & 55.7 (18.7) & 9.3 (3.3) \\
\hline Abseamed & 3107 & $57.3(10.2)$ & $9.1(2.4)$ \\
\hline Accofil & 3159 & $51.7(14.9)$ & $10.8(3.4)$ \\
\hline Amgevita & 4912 & $48.1(17.0)$ & $10.0(3.2)$ \\
\hline Bemfola & 2973 & 46.1 (19.3) & $11.0(4.1)$ \\
\hline Benepali & 3790 & $52.6(11.1)$ & $9.7(2.2)$ \\
\hline Binocrit & 3109 & $57.5(10.3)$ & $9.0(2.3)$ \\
\hline Blitzima & 2226 & $54.9(14.3)$ & $9.6(3.0)$ \\
\hline $\begin{array}{l}\text { Epoetin Alfa } \\
\text { Hexal }\end{array}$ & 3094 & $57.7(10.5)$ & $9.0(2.3)$ \\
\hline Erelzi & 4091 & $50.8(10.3)$ & $10.1(1.9)$ \\
\hline $\begin{array}{l}\text { Filgrastim } \\
\text { Hexal }\end{array}$ & 2506 & $57.1(12.0)$ & $9.4(2.6)$ \\
\hline Flixabi & 3380 & $54.4(11.6)$ & $10.0(3.2)$ \\
\hline Grastofil & 3167 & $56.1(12.7)$ & $9.6(2.7)$ \\
\hline Imraldi & 4905 & $50.3(14.6)$ & $9.7(2.7)$ \\
\hline Inflectra & 3471 & $54.1(11.6)$ & $10.2(3.2)$ \\
\hline Inhixa & 3468 & $63.8(6.2)$ & $7.5(1.2)$ \\
\hline Lusduna & 3608 & $56.2(17.9)$ & $9.1(3.2)$ \\
\hline Movymia & 1798 & $58.0(12.1)$ & $8.7(2.0)$ \\
\hline Nivestim & 2887 & $57.4(12.6)$ & $9.4(2.8)$ \\
\hline Omnitrope & 3055 & $56.4(7.4)$ & $9.0(1.8)$ \\
\hline Ovaleap & 2643 & 42.7 (20.2) & $11.5(3.9)$ \\
\hline Ratiograstim & 2581 & $60.3(8.8)$ & $8.0(1.4)$ \\
\hline Remsima & 3438 & $52.2(15.2)$ & $10.9(4.7)$ \\
\hline Retacrit & 4862 & 48.9 (17.3) & $10.7(3.7)$ \\
\hline Ritemvia & 2115 & $56.0(13.9)$ & $9.4(3.0)$ \\
\hline Rituzena & 2195 & $54.5(14.1)$ & $9.6(3.0)$ \\
\hline Rixathon & 2842 & $55.2(13.3)$ & $9.6(3.2)$ \\
\hline Riximyo & 2707 & $56.4(12.5)$ & $9.5(3.1)$ \\
\hline Silapo & 3276 & 47.5 (15.6) & $11.0(3.5)$ \\
\hline Solymbic & 4801 & $48.8(15.7)$ & $9.9(3.0)$ \\
\hline Terrosa & 1795 & $57.9(12.1)$ & $8.7(2.0)$ \\
\hline Tevagrastim & 2576 & $60.3(8.8)$ & $8.0(1.4)$ \\
\hline Thorinane & 2849 & $63.2(5.9)$ & $7.6(1.2)$ \\
\hline Truxima & 2752 & $55.1(14.6)$ & $9.7(3.4)$ \\
\hline Zarzio & 2502 & $56.4(13.6)$ & 9.7 (3.3) \\
\hline
\end{tabular}

FKGL, Flesch-Kincaid Grade Level; FRE, Flesch Reading Ease.

what it is used for'. In addition, taking into account the central values for each section, none of them was easy to understand, according to the qualitative scale established for the Flesch Index, as they all had values below 70: the Annex and sections 3 and 5 were standard; section 2 was fairly difficult; and sections 1 and 4 were difficult.
In the comparative study of the six types of biosimilars (erythropoietins, granulocyte-colony stimulating factors, heparins, hormones, monoclonal antibodies and tumour necrosis factor alpha inhibitors), we observed descriptive differences between them in terms of all three of the quantitative variables (figure 2 and table 4 ). For the length of the package leaflets, the following decreasing order was established, from the type of biosimilars with the longest package leaflet to the shortest: tumour necrosis factor alpha inhibitors $>$ heparins $>$ monoclonal antibodies $>$ erythropoietins $>$ hormones $>$ granulocyte-colony stimulating factors. In terms of readability, heparins were the biosimilars with the easiest package leaflets to understand, and tumour necrosis factor alpha inhibitors were those with the most difficult. In the subsequent hypothesis tests, we did not include the heparins or the tumour necrosis factor alpha inhibitors, as the samples of these types of biosimilars were too small for the results to be statistically meaningful $(n=2)$. Taking into account this exclusion, the descriptive differences observed previously were not statistically significant $(p>0.05)$.

When we compared the quantitative variables relative to the date of first authorisation of the biosimilars, there were no statistically significant differences $(p>0.05)$ in any of the three, between the biosimilars authorised in the period 2006-2014 ( $\mathrm{n}=18)$ and those authorised later $(n=17)$. Despite this, we did observe a slight decrease over time, both in the length of the package leaflets and in their readability (figure 3 ).

Finally, when we compared the biosimilars with their reference medicines, we observed no statistically significant differences $(p>0.05)$ in any of the three quantitative variables, since the descriptive statistics were practically the same for the two groups.

\section{DISCUSSION}

The objective of the present study was to determine the length and the readability of the package leaflets of the biosimilars authorised by the EMA. In 2017, the number of authorised biosimilars in Europe was growing more quickly than in previous years, ${ }^{28}$ and, in addition, the rate at which they are prescribed is also increasing compared with their reference medicines. ${ }^{37}$

Our results show that the package leaflets analysed are longer than those of non-biological medicines, ${ }^{35}$ and of non-biosimilar biological medicines. ${ }^{36}$ Excessive information in the package leaflets does not meet the requirements of patients. ${ }^{17}$ This becomes more important for biosimilars, the majority of which are prescribed in the treatment of serious diseases, such as cancer, ${ }^{38}$ as patients suffering from these conditions may experience a high degree of anxiety from the moment they receive the diagnosis. ${ }^{39}$

None of the package leaflets analysed was easy to understand, and the readability level of each package leaflet was higher than is recommended for health-related written materials. These results, therefore, do not comply 


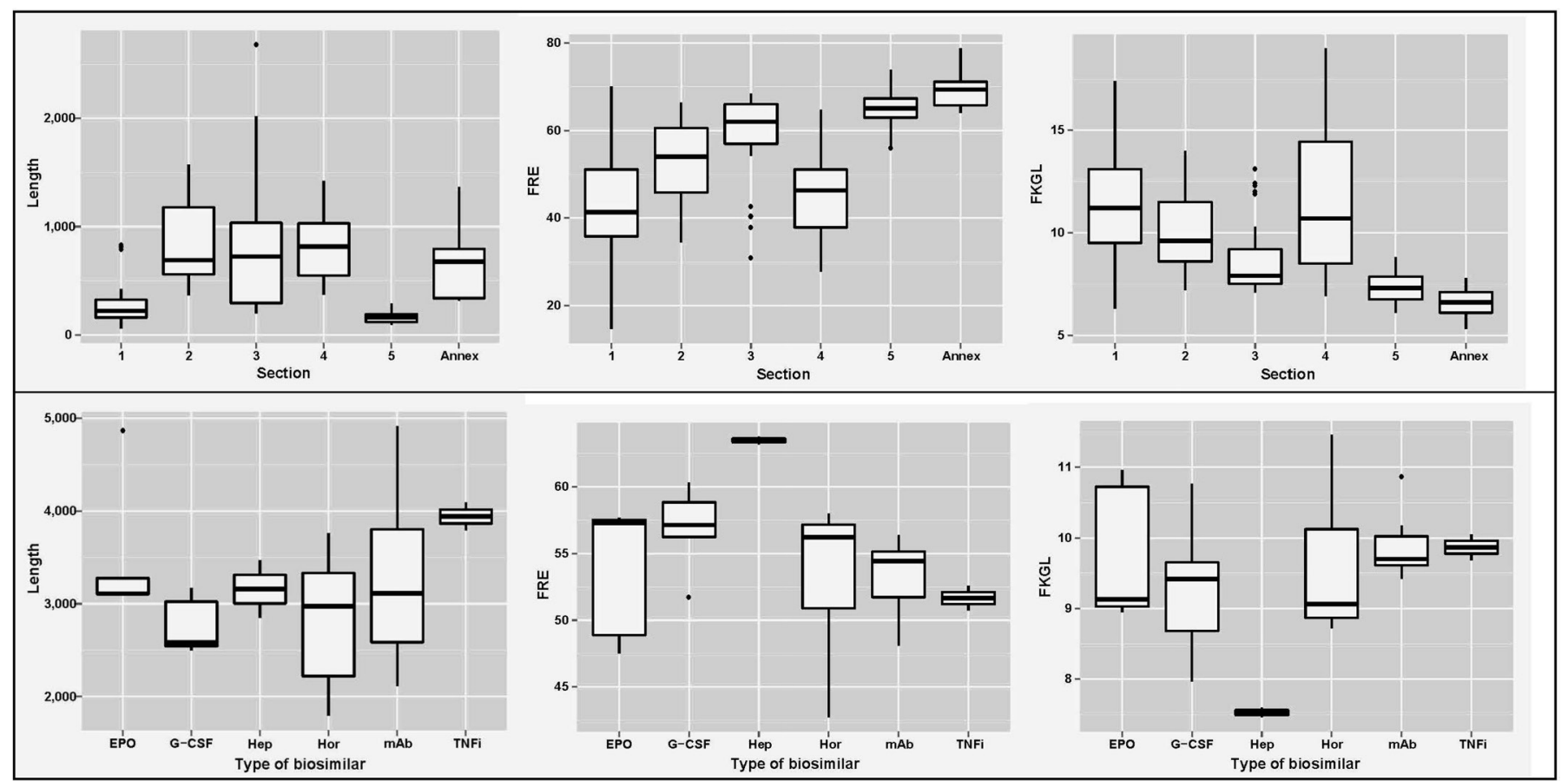

Figure 2 Box plots of quantitative variables taking into account the package leaflet section and the type of medicine.

with the European regulations, according to which the package leaflet must be easy to read. ${ }^{22}$ The two readability formulas used in the present study include the length of the words (number of syllables per word) and the length of the sentences (number of words per sentence) as variables. These two factors are referred to in the guideline published by the European Commission, where the use of words with few syllables and short sentences is recommended, in order to facilitate understanding of the package leaflet. ${ }^{16}$ So our results show that these recommendations were not followed either, and in this they coincide with the results of a study of the readability of non-biosimilar biological medicines. ${ }^{25}$ These results were also similar to those reported from other studies that used the same formulas with different health-related written materials, such as patient information leaflets for health procedures, ${ }^{40}$ discharges summaries ${ }^{41}$ and also online materials. ${ }^{42}$

The lack of readability that the package leaflets may exhibit could lead to not all patients reading them, and even to a certain degree of alarm in patients who do read them, which could reduce adherence to the treatment. ${ }^{43}$ In contrast, it has been demonstrated that written materials addressed to patients that are easily understood by them improve doctor-patient relations, and complement the information provided during visits. ${ }^{44}$ These findings agree with the results reported by Burgers $e t a l,{ }^{45}$ who found that patients thought it necessary to write package leaflets in a language that is easier to understand. It therefore seems clear that the package leaflet should provide all patients with sufficient confidence in the medicine to enhance a correct use, but they may not be doing so. By shortening the length of the text in package leaflets and increasing their readability, according to the recommendations in the 2009 European Commission guideline, this situation could be improved.

When we compared the different sections of the package leaflets, we observed differences between them in both length and readability. The most difficult section to understand was section 1 ('What $\mathrm{X}$ is and what it is used for'), which offers information on the therapeutic indications and is considered the most important by patients. ${ }^{31}$ Section 4 ('Possible side effects') was the second most difficult section and, despite being judged to be very important by patients ${ }^{46}$ it usually contains lists of complex medical terms, ${ }^{47}$ which was the case in the majority of the package leaflets analysed in the present study. This can cause negative attitudes in patients when they are considering using the medicine, which seems to make it clear that this section needs to be written using a language which is less alarming for the patient. ${ }^{48}$ On the other hand, the information has to be truthful and accurate according to updated evidence. ${ }^{28}$

The most easy section to understand was the Annex, which contains information concerning how to handle the device that is used to administer the medicine, followed by section 5 ('How to store X'), which explains how the medicine should be kept. On the other hand, the longest sections were the warning concerning possible side effects, the dosing instructions, how to handle administration devices and the contraindications, results which were similar to those of Fuchs et al $^{35}$

In relation to the type of biosimilar, the readability of the heparin package leaflets was notable since, according to the FRE scale, they were classified as standard, whereas all the other types of biosimilars were classified as less readable according to this scale. In fact, heparins were the only one of the groups in which all the medicines are 
Table 3 Descriptive statistics of length and readability indexes by package leaflet section

\begin{tabular}{|c|c|c|c|c|c|c|}
\hline Variable & Package leaflet section & $\mathbf{n}$ & Median & $Q_{1}-Q_{3}$ & Min-Max & P value $^{*}$ \\
\hline \multicolumn{7}{|l|}{ Length } \\
\hline & & & & & & $<0.001$ \\
\hline & 1. What $X$ is and what it is used for & 35 & 222 & $160-326$ & $58-829$ & \\
\hline & $\begin{array}{l}\text { 2. What you need to know before you }<\text { take }> \\
<\text { use }>X\end{array}$ & 35 & 690 & $558-1180$ & $366-1573$ & \\
\hline & 3. How to $<$ take $><$ use $>$ X & 35 & 724 & $294-1036$ & 199-2682 & \\
\hline & 4. Possible side effects & 35 & 817 & $547-1030$ & $371-1420$ & \\
\hline & 5. How to store $X$ & 35 & 164 & $117-193$ & $92-288$ & \\
\hline & Annex & 16 & 678 & $339-794$ & $318-1363$ & \\
\hline
\end{tabular}

\begin{tabular}{|c|c|c|c|c|c|c|}
\hline & & & & & & $<0.001$ \\
\hline & 1. What $X$ is and what it is used for & 35 & 41.3 & $35.8-51.1$ & $14.6-70.0$ & \\
\hline & $\begin{array}{l}\text { 2. What you need to know before you }<\text { take }> \\
<\text { use }>X\end{array}$ & 35 & 54.0 & $45.9-60.6$ & $34.5-66.4$ & \\
\hline & 3. How to $<$ take $><$ use $>$ X & 35 & 62.0 & $57.0-66.0$ & $30.9-68.4$ & \\
\hline & 4. Possible side effects & 35 & 46.3 & $37.9-51.1$ & $27.7-64.7$ & \\
\hline & 5. How to store $X$ & 35 & 65.1 & $63.0-67.4$ & $56.0-73.9$ & \\
\hline & Annex & 16 & 69.4 & $65.8-71.2$ & $64.1-78.8$ & \\
\hline \multicolumn{7}{|l|}{ FKGL } \\
\hline & & & & & & $<0.001$ \\
\hline & 1. What $X$ is and what it is used for & 35 & 11.2 & $9.5-13.1$ & $6.3-17.4$ & \\
\hline & $\begin{array}{l}\text { 2. What you need to know before you }<\text { take }> \\
<\text { use }>X\end{array}$ & 35 & 9.6 & $8.6-11.5$ & $7.2-14.0$ & \\
\hline & 3. How to $<$ take $><$ use $>$ X & 35 & 7.9 & $7.5-9.2$ & $7.1-13.1$ & \\
\hline & 4. Possible side effects & 35 & 10.7 & $8.5-14.5$ & $6.9-19.0$ & \\
\hline & 5. How to store $X$ & 35 & 7.3 & $6.8-7.9$ & $6.1-8.8$ & \\
\hline & Annex & 16 & 6.6 & $6.1-7.1$ & $5.3-7.8$ & \\
\hline
\end{tabular}

${ }^{*}$ Kruskal-Wallis test.

FKGL, Flesch-Kincaid Grade Level; FRE, Flesch Reading Ease; Max, maximum; Min, minimum; $Q_{1}$, first quartile; $Q_{3}$, third quartile.

prescribed within the area of primary healthcare. Notwithstanding this initial finding, our observation needs to be corroborated in larger samples.

We did observe that the more recently authorised biosimilars had shorter package leaflets, although this did not lead to greater readability. Based on this result, it would be possible to conclude that the length of the texts is not necessarily related to how easy they are to understand. Such a conclusion would agree with the results of Piñero et $a l,{ }^{36}$ who found no statistically significant correlation between the length of package leaflets and the results of applying the readability formulas to them.

In addition, the difficulty in understanding the package leaflets was independent of whether we were dealing with the biosimilar medicinal product or the reference medicine. Therefore, patients' need for information continues to be an issue for both types of medicines: biosimilars as well as the original reference medicines. Regulatory bodies and the majority of the literature on biosimilars focus on aspects such as safety, efficiency, quality and cost; so patient information continues to be undervalued and therefore so is the empowering of patients within a context of healthcare decision-making.

In this study, no patients were consulted and this could be a limitation. However, these formulas can be considered as a first step to identify readability problems independently of the patients. Besides, the applied readability formulas can predict objectively the understanding level of package leaflets. In this way, different studies have obtained a consistency between the results obtained by applying readability formulas and those using user testing. ${ }^{49}$

Another limitation was package leaflet is not the only written source of information related the medicines. There are also other patient information leaflets developed by many clinicians to aim an adequate understanding of the information by patient. ${ }^{50}$ Nevertheless, most people use the internet as their first source of health information. In this sense, package leaflets evaluated are accessible online in the EMA website, independently of administration healthcare setting. 
Table 4 Descriptive statistics of length and readability indexes by type of biosimilar

\begin{tabular}{llclll}
\hline Variable & Type of medicine & $\mathbf{n}$ & Median & $\mathbf{Q}_{\mathbf{1}}-\mathbf{Q}_{\mathbf{3}}$ & Min-Max \\
\hline Length & & & & \\
& & & & & \\
& EPO & 5 & 3109 & $3107-3276$ & $3094-4862$ \\
& G-CSF & 7 & 2581 & $2541-3023$ & $2502-3167$ \\
& Hep & 2 & 3159 & $3004-3313$ & $2849-3468$ \\
& Hor & 7 & 2973 & $2221-3332$ & $1795-3760$ \\
& MAb & 12 & 3111 & $2587-3804$ & $2115-4912$ \\
FRE & TNFi & 2 & 3941 & $3865-4016$ & $3790-4091$
\end{tabular}

$>0.05$

$\begin{array}{lrrrr}\text { EPO } & 5 & 57.3 & 48.9-57.5 & 47.5-57.7 \\ \text { G-CSF } & 7 & 57.1 & 56.2-58.8 & 51.7-60.3 \\ \text { Hep } & 2 & 63.5 & 63.3-63.6 & 63.2-63.8 \\ \text { Hor } & 7 & 56.2 & 50.9-57.2 & 42.7-58.0 \\ \text { mAb } & 12 & 54.4 & 51.7-55.2 & 48.1-56.4 \\ \text { TNFi } & 2 & 51.7 & 51.2-52.1 & 50.8-52.6\end{array}$

FKGL

\begin{tabular}{lllll} 
EPO & 5 & 9.1 & $9.0-10.7$ & $9.0-11.0$ \\
G-CSF & 7 & 9.4 & $8.7-9.7$ & $8.0-10.8$ \\
Hep & 2 & 7.5 & $7.5-7.6$ & $7.5-7.6$ \\
Hor & 7 & 9.1 & $8.9-10.1$ & $8.7-11.5$ \\
mAb & 12 & 9.7 & $9.6-10.0$ & $9.4-10.9$ \\
TNFi & 2 & 9.9 & $9.8-10.0$ & $9.7-10.1$ \\
\hline
\end{tabular}

${ }^{*}$ Kruskal-Wallis test (heparins and tumour necrosis factor alpha inhibitors were excluded of the hypothesis test).

EPO, erythropoietins; FKGL, Flesch-Kincaid Grade Level; FRE, Flesch Reading Ease; G-CSF, granulocyte-colony stimulating factors; Hep, heparins; Hor, hormones; mAb, monoclonal antibodies; Max, maximum; Min, minimum; $Q_{1}$, first quartile; $Q_{3}$, third quartile; TNFi, tumour necrosis factor alpha inhibitors.

\section{CONCLUSION}

The European Commission has made efforts to contribute to suitable writing of package leaflets, through the publication of its guideline in 2009. The marketing authorisation holders of biosimilars, medicines which have been authorised more recently than others, should have implemented those recommendations to a greater degree, as most of them were authorised in the EU after
2009. To that end, it would always be possible, before publication of the package leaflet, to perform readability tests directly with the target patients (as is recommended in the guideline), and to apply readability formulas and assess the results as a prior step. Finally, the competent organisations could be informed about package leaflets for authorised biosimilar medicines may not fulfil the function for which they were designed, which could have
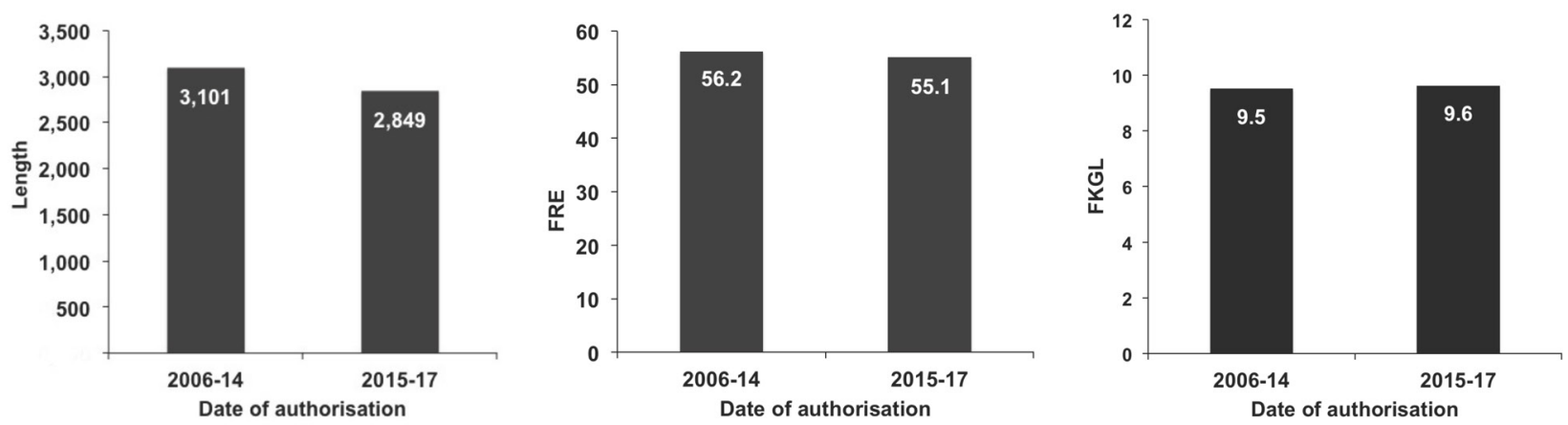

Figure 3 Medians of the quantitative variables taking into account the date of first authorisation. 
a negative effect on the use of the medicines by the user or patient.

Contributors MAP-L acquired, analysed and interpreted data and drafted and approved the final submitted manuscript. CF-E contributed expertise in interpretation and analysis and helped revise the draft manuscript. PM conceived the study, analysed and interpreted data and drafted and approved the final submitted manuscript. CFL made suggestions for data analysis and approved the final submitted manuscript. ELM conceived the study, analysed and interpreted data and drafted and approved the final submitted manuscript. All authors reviewed and agreed on the submitted version of the manuscript.

Funding The authors have not declared a specific grant for this research from any funding agency in the public, commercial or not-for-profit sectors.

Competing interests None declared.

Patient consent for publication Not required.

Provenance and peer review Not commissioned; externally peer reviewed.

Data sharing statement № additional data are available.

Open access This is an open access article distributed in accordance with the Creative Commons Attribution Non Commercial (CC BY-NC 4.0) license, which permits others to distribute, remix, adapt, build upon this work non-commercially, and license their derivative works on different terms, provided the original work is properly cited, appropriate credit is given, any changes made indicated, and the use is non-commercial. See: http://creativecommons.org/licenses/by-nc/4.0/.

\section{REFERENCES}

1. European Medicines Agency. Biosimilars in the EU. Information guide for healthcare professionals. $2017 \mathrm{http}: / / w w w . e m a . e u r o p a . e u /$ docs/en_GB/document_library/Leaflet/2017/05/WC500226648.pdf (accessed13 Jul 2017).

2. European Medicines Agency. Guideline on similar biological medicinal products. 2014 http://www.ema.europa.eu/docs/en_GB/ document_library/Scientific_guideline/2014/10/WC500176768.pdf (accessed 5 Sep 2017).

3. McCamish M, Pakulski J, Sattler C, et al. Toward interchangeable biologics. Clin Pharmacol Ther 2015;97:215-7.

4. Khraishi M, Stead D, Lukas M, et al. Biosimilars: A multidisciplinary perspective. Clin Ther 2016;38:1238-49.

5. Schellekens $\mathrm{H}$, Moors E. Clinical comparability and European biosimilar regulations. Nat Biotechnol 2010;28:28-31.

6. Hennessy S, Leonard CE, Platt R. Assessing the safety and comparative effectiveness of follow-on biologics (biosimilars) in the United States. Clin Pharmacol Ther 2010;87:157-9.

7. Simoens S. Biosimilar medicines and cost-effectiveness. Clinicoecon Outcomes Res 2011;3:29-36.

8. Schellekens H, Moors E. Biosimilars or semi-similars? Nat Biotechnol 2015;33:19-20.

9. Casey D. Key strategic factors for stakeholders in the current global biosimilar market. Drug Discov Today 2016;21:208-11.

10. Rompas S, Goss T, Amanuel S, et al. Demonstrating value for biosimilars: A conceptual framework. Am Health Drug Benefits 2015;8:129-39.

11. Skingle D. Biosimilars: what do patients need to consider? $R M D$ Open 2015;1:e000141.

12. Miller KL, Lanthier M. Regulatory watch: Innovation in biologic new molecular entities: 1986-2014. Nat Rev Drug Discov 2015;14:83.

13. Raynor DK. User testing in developing patient medication information in Europe. Res Social Adm Pharm 2013;9:640-5.

14. Directive 2001/83/EC of the European Parliament and of the Council of 6 November 2001 on the Community code relating to medicinal products for human use. OJ http://eur-lex.europa.eu/legal-content/ EN/TXT/PDF/?uri=CELEX:32001L0083\&from=en.

15. Hamrosi KK, Raynor DK, Aslani P. Enhancing provision of written medicine information in Australia: pharmacist, general practitioner and consumer perceptions of the barriers and facilitators. BMC Health Serv Res 2014;14:183.

16. European Commission. Enterprise and Industry Directorate-General. Guideline on the readability of the labelling and package leaflet of medicinal products for human use. 2009. Revision 1. http://ec. europa.eu/health/sites/health/files/files/eudralex/vol-2/c/2009_01_ 12_readability_guideline_final_en.pdf (accessed 12 Nov 2017).

17. van Beusekom MM, Grootens-Wiegers P, Bos MJ, et al. Low literacy and written drug information: information-seeking, leaflet evaluation and preferences, and roles for images. Int J Clin Pharm 2016;38:1372-9.

18. Nutbeam D. Health promotion glossary. Health Promot Int 1998;13:349-64.

19. Smith PC, Brice JH, Lee J. The relationship between functional health literacy and adherence to emergency department discharge instructions among Spanish-speaking patients. J Natl Med Assoc 2012;104:521-7.

20. Batterham RW, Hawkins M, Collins PA, et al. Health literacy: applying current concepts to improve health services and reduce health inequalities. Public Health 2016;132:3-12.

21. DuBay WH. Smart language: readers, readability, and the grading of text. Costa Mesa, CA: Impact Information, 2007. http://www. impact-information.com/impactinfo/newsletter/smartlanguage02.pdf. (accessed 17 Oct 2017).

22. Directive 2004/27/EC of the European Parliament and of the Council of 31 March 2004 amending Directive 2001/83/EC on the Community code relating to medicinal products for human use. $O J \mathrm{http}: / /$ eur-lex. europa.eu/legal-content/EN/TXT/PDF/?uri=CELEX:32004L0027\& from $=\mathrm{EN}$.

23. Donnelly KZ, Thompson R. Medical versus surgical methods of early abortion: protocol for a systematic review and environmental scan of patient decision aids. BMJ Open 2015;5:e007966.

24. Dyson MP, Shave K, Gates A, et al. Which outcomes are important to patients and families who have experienced paediatric acute respiratory illness? Findings from a mixed methods sequential exploratory study. BMJ Open 2017;7:e018199.

25. Piñero-López MÁ, Modamio P, Lastra CF, et al. Readability assessment of package inserts of biological medicinal products from the European medicines agency website. Drug Saf 2014;37:543-54.

26. Doak CC, Doak LG, Root JH. Teaching patients with low literacy skills. 2nd ed. Philadelphia: JB Lippincott Company, 1996:96;16M.

27. Konara CS, Barnard RT, Hine D, et al. The tortoise and the hare: evolving regulatory landscapes for biosimilars. Trends Biotechnol 2016;34:70-83.

28. European Medicines Agency. European Public Assessment Reports. 2017 http://www.ema.europa.eu/ema/index.jsp?curl=pages/ medicines/landing/epar_search.jsp\&mid=WCOb01ac058001d124 (accessed 31 Aug 2017).

29. Declerck P, Farouk-Rezk M, Rudd PM. Biosimilarity versus manufacturing change: two distinct concepts. Pharm Res 2016;33:261-8.

30 European Medicines Agency. Product-information templates. 2017. http://www.ema.europa.eu/ema/index.jsp?curl=pages/ regulation/document_listing/document_listing_000134.jsp\&mid= WC0b01ac0580022c59 (accessed 31 Aug 2017).

31. Fuchs J, Hippius M, Schaefer M. A survey of package inserts use by patients. Hosp J Pharm Eur 2005:29-31 http://www.paintconsult.com/fileadmin/editorial/downloads/publikationen/PAINTConsult_package_inserts_use_patients.pdf (accessed 13 Nov 2017).

32. Flesch R. A new readability yardstick. J Appl Psychol 1948;32:221-33.

33. Kincaid JP, Fishburne RP, Rogers RL, et al. Derivation of new readability formulas (automated readability index, fog count and Flesch reading ease formula) for navy enlisted personnel. Research Branch Report. Millington, TN: US Naval Air Station, Memphis: Naval Technical Training, 1975:8-75. http://www.dtic.mil/dtic/tr/fulltext/u2/ a006655.pdf. (accessed16 Nov 2017).

34. Wang LW, Miller MJ, Schmitt MR, et al. Assessing readability formula differences with written health information materials: application, results, and recommendations. Res Social Adm Pharm 2013;9:503-16.

35. Fuchs J, Werner S, Scheunpflug C, et al. Excessive medical information increase in package inserts. Int $J$ Clin Pharmacol Ther 2010;48:781-90.

36. Piñero-López MÁ, Modamio P, Lastra CF, et al. Readability analysis of the package leaflets for biological medicines available on the internet between 2007 and 2013: an analytical longitudinal study. $J$ Med Internet Res 2016;18:e100.

37. Chapman SR, Fitzpatrick RW, Aladul MI. Knowledge, attitude and practice of healthcare professionals towards infliximab and insulin glargine biosimilars: result of a UK web-based survey. BMJ Open 2017;7:e016730.

38. Mayden KD, Larson P, Geiger D, et al. Biosimilars in the United States: considerations for oncology advanced practitioners. J Adv Pract Oncol 2015;6:108-16.

39. Morris M, Friedemann Smith C, Boxell E, et al. Quantitative evaluation of an information leaflet to increase prompt helpseeking for gynaecological cancer symptoms. BMC Public Health 2016;16:374. 
40. Gargoum FS, O'Keeffe ST. Readability and content of patient information leaflets for endoscopic procedures. Ir J Med Sci 2014;183:429-32.

41. Choudhry AJ, Baghdadi YM, Wagie AE, et al. Readability of discharge summaries: with what level of information are we dismissing our patients? Am J Surg 2016;211:631-6.

42. Santos PJF, Daar DA, Paydar KZ, et al. Readability of online materials for rhinoplasty. World J Plast Surg 2018;7:89-96.

43. Vinker S, Eliyahu V, Yaphe J. The effect of drug information leaflets on patient behavior. Isr Med Assoc J 2007;9:383-6.

44. McCartney M. Patient information leaflets: "a stupid system". BMJ 2013;347:f4748.

45. Burgers C, Beukeboom CJ, Sparks L, et al. How (not) to inform patients about drug use: use and effects of negations in Dutch patient information leaflets. Pharmacoepidemiol Drug Saf 2015;24:137-43.
46. Pires $\mathrm{C}$, Vigário M, Cavaco A. Factors influencing subjects' comprehension of a set of medicine package inserts. Int J Clin Pharm 2016;38:888-98.

47. Pires CM, Cavaco AM. Exploring the perspectives of potential consumers and healthcare professionals on the readability of a package insert: a case study of an over-the-counter medicine. Eur $J$ Clin Pharmacol 2014;70:583-8.

48. Herber OR, Gies V, Schwappach D, et al. Patient information leaflets: informing or frightening? A focus group study exploring patients' emotional reactions and subsequent behavior towards package leaflets of commonly prescribed medications in family practices. BMC Fam Pract 2014;15:163.

49. Smith SG, Wolf MS, Obichere A, et al. The development and testing of a brief ('gist-based') supplementary colorectal cancer screening information leaflet. Patient Educ Couns 2013;93:619-25.

50. de Bont EG, Alink M, Falkenberg FC, et al. Patient information leaflets to reduce antibiotic use and reconsultation rates in general practice: a systematic review. BMJ Open 2015;5:e007612. 